\title{
Human Information Behavior
}

\author{
Glenn J. Browne $\cdot$ Christy M. K. Cheung • \\ Armin Heinzl • René Riedl
}

Published online: 20 December 2016

(C) Springer Fachmedien Wiesbaden 2016

Human information behavior may be conceptualized as "the totality of human behavior in relation to sources and channels of information, including both active and passive information seeking, and information use" (Wilson 2000, p. 49). It can be understood as an overarching research trajectory attempting to develop generalizable explanations of behavioral phenomena observable when humans acquire and process information. Thus, human information behavior is not limited to the isolated consideration of a specific type of task such as decision-making. Instead, it can be interpreted as a boundary spanner serving as a frame for IS research and uncovering the aforementioned phenomena in computer-mediated settings.

Prof. Dr. G. J. Browne

Information Systems and Quantitative Sciences, Rawls College of Business, Texas Tech University, Lubbock, TX 79409, USA e-mail: glenn.browne@ttu.edu

Prof. Dr. C. M. K. Cheung

Department of Finance and Decision Sciences, Hong Kong Baptist University, 34 Renfrew Road, Kowloon Tong, Kowloon, Hong Kong, China

e-mail: ccheung@hkbu.edu.hk

Prof. Dr. A. Heinzl ( $\square)$

General Management and Information Systems, University of Mannheim, 68131 Mannheim, Germany

e-mail: heinzl@uni-mannheim.de

Prof. Dr. R. Riedl

School of Management, University of Applied Sciences Upper Austria, Wehrgrabengasse 1-3, 4400 Steyr, Austria

e-mail: rene.riedl@fh-steyr.at

Prof. Dr. R. Riedl

Department of Business Informatics, Information Engineering, Johannes Kepler University, Linz, Austria
Unfortunately, extant research in IS has largely neglected the entity "information" and the associated behavioral phenomena that occur when information is sought, processed, and shared. Hemmer and Heinzl (2011) have conducted a comprehensive literature review of this topic, and one of their key findings was that the IS discipline lacks a cumulative research tradition concerning information and related behaviors. Thus, it is the goal of this special issue of BISE to emphasize the importance of human information behavior in information systems research. Information underlies all human behavior, including the decision making and problem solving that people perform constantly in their everyday lives. However, many of the critical characteristics of information that drive business and personal decision making deserve far more attention from researchers. For example, information search and the filtering of information are critical to all decision making and are the conceptual foundations of the "big data" revolution, but theoretical development and systematic investigations of these foundations are still needed and are simply taken for granted by practitioners of data mining and business analytics. As another example, in systems development, gaps may exist between information requirements (i.e., information that is objectively necessary to accomplish a task), information needs (i.e., information that is subjectively considered to be relevant to accomplish a task), information demand (i.e., information that is sought or deliberately not sought by a person in a specific decision-making situation), and information use (i.e., the available information an analyst or other decision maker chooses to utilize to accomplish a task). The potential causes of these gaps (e.g., characteristics of the person, such as risk aversion or curiosity, and characteristics of the task, such as variability or importance) are not well understood, and thus systematic scientific investigation is necessary. 
Technology is a critical means for facilitating human information behavior, but it is only a means; information is an end, the factor of ultimate interest and value. As Broadbent et al. (2003, p. 10) stated succinctly, "To put it simply, it's not about the box; it's about what's inside the box." And as noted by Tallon et al. (2013-2014, p. 142), "There is growing recognition among business and information systems (IS) executives that data, or more precisely, information, may be the only inimitable IT resource that can create a sustainable competitive advantage." Therefore, understanding human information behavior is critical to information systems research.

This special issue is rooted in the theme track for ICIS 2015, "Exploring the Information Frontier." That track established human information behavior as a critical area of study in information systems research. We are proud to present three papers in this special issue that address gaps in our understanding of human information behavior.

The first paper, by Roman Tilly, Oliver Posegga, Kai Fischbach, and Detlef Schoder, investigates data and information quality (DIQ) in the context of social information systems. The authors argue persuasively that existing research on human information behavior has focused primarily on individual level behavior and that collaborative and collective search, filtering, and use of information have not received appropriate attention. The authors define a taxonomy of DIQ conceptualizations and use those conceptualizations to analyze information behavior in social information systems in the existing literature. The result is the identification of gaps in the literature and opportunities for research into human information behavior at the group level. The paper provides an important contribution to a previously unexplored area of research.

The second paper, by Lauri Wessel, Martin Gersch, and Erik Harloff, investigates information pathologies, that is, distortions in information search, analysis, use, or sharing, that result from the cognition or motivation of human actors in decision-making contexts. The particular focus of this paper is on how information pathologies occur at the societal level. The authors discuss pathologies in human information behavior generally and then provide a fascinating example of a societal-level pathology using a case study of the Electronic Health Card (EHC) in Germany. The authors argue that information concerning the EHC became increasingly distorted over time and resulted in an information pathology. The paper is one of the first to investigate societal-level information pathologies and provides a valuable contribution to the literature.

The third paper, by Kathrin Figl, provides an overview of cognitive effort in process model comprehension. The focus is on information seeking in process models and on comprehension as users of the process models assimilate and accommodate the information into their existing mental models. As noted by the author, the research extends "human information behavior research on information delivery through IS to the area of process modeling by looking at the visualization of process models and the cognitive fit between process models and tasks and users." The result is an important contribution for information systems researchers.

The special issue papers were selected utilizing a rigorous review process in which each paper was revised at least twice by the authors. The result, we believe, is a group of excellent papers that represent the goals of the special issue particularly well.

We thank all of the reviewers who contributed their time and expertise to the reviews for these papers. Their help was greatly appreciated and contributed significantly to the quality of the papers in this issue.

\section{References}

Broadbent M, McDonald M, Hunter R (2003) Does IT matter? An HBR debate: letter from Marianne Broadbent, Mark McDonald, and Richard Hunter. Harv Bus Rev 81(6):10

Hemmer E, Heinzl A (2011) Where is the "I" in "IS research"? The quest for a coherent research stream in the context of human information behavior. In: Heinzl A, Buxmann $\mathrm{P}$, Wendt $\mathrm{O}$, Weitzel $\mathrm{T}$ (eds) Theory-guided modeling and empiricism in information systems research. Physica, Heidelberg, pp 223-246

Tallon PP, Ramirez RV, Short JE (2013-2014) The information artifact in IT governance: toward a theory of information governance. J Man Inf Syst 30(3):141-147

Wilson TD (2000) Human information behavior. Inform Sci $3(2): 49-55$ 